\title{
Influence of Electrochemical Potentials on the Tribological Behavior of Silicon Carbide and Diamond-Coated Silicon Carbide
}

\author{
Tobias Amann $^{1} \cdot$ Andreas Kailer $^{1} \cdot$ Mathias Herrmann $^{2}$
}

Received: 7 August 2015/Revised: 2 October 2015/Accepted: 5 October 2015/Published online: 22 October 2015

(C) Springer International Publishing Switzerland 2015

\begin{abstract}
Due to their high corrosion stability in combination with advantageous tribological performance, sintered silicon carbide ceramics are widely used in industrial applications. Both the corrosion stability and the tribological behavior can be affected by electrochemical processes. Tribological investigations were carried out using an electrochemical three electrode setup. The influence of electrochemical potentials on the friction and wear behavior of different sintered $\mathrm{SiC}$ materials in $1 \mathrm{M} \mathrm{NaCl}-$ solution was investigated to analyze the complex interplay between mechanical, chemical, and electrochemical interactions during tribo-corrosion. The results revealed that friction and wear of $\mathrm{SiC}$ were decreased under cathodic electrochemical polarization depending on the material composition. In addition, tribological tests at different electrochemical potentials showed that the coefficient of friction can be switched immediately. The results indicated that the tribological behavior is strongly affected by the increased double-layer repulsion due to the electrochemical potentials, which supports the hydrodynamic lubrication.
\end{abstract}

Tobias Amann

tobias.amann@iwm.fraunhofer.de

Andreas Kailer

andreas.kailer@iwm.fraunhofer.de

Mathias Herrmann

mathias.herrmann@ikts.fraunhofer.de

1 Fraunhofer Institute for Mechanics of Materials IWM, Woehlerstrae 11, 79108 Freiburg, Germany

2 Fraunhofer Institute for Ceramic Technologies and Systems IKTS, Winterbergstrae 28, 01277 Dresden, Germany
Keywords Potential-controlled friction - Electric conductive-sintered silicon carbide $\cdot$ Diamond-coated silicon carbide $\cdot$ Wear analysis $\cdot$ Friction mechanisms

\section{Introduction}

Due to their low friction in aqueous media and high corrosion and wear resistance silicon carbide ceramics $(\mathrm{SiC})$ have become standard materials for slide bearings and face seals in pumps [1-3]. However, in aggressive media chemical or electrochemical corrosion processes of these materials may occur. Celis et al. [4] discussed the complex interplay between mechanical and chemical mechanisms during tribo-corrosion. Tribochemical reactions of water with the ceramic contact surfaces are important for a stable lubrication regime [5]. It is assumed that these chemical reactions are responsible for the formation of superlubricious phases i.e., to tribological regimes with nearly zero friction $[6,7]$. In an aqueous environment, the friction coefficient of $\mathrm{SiC}$ sliding pairs reaches values below 0.1 [8] and tribochemical reactions in the sliding contact cause a smoothening of the sliding surfaces [9-11]. These tribochemical reactions cause mild wear conditions, and the removal of surface asperities favors hydrodynamic lubrication even at very low lubricant viscosity. Knowledge of the electrochemical and tribochemical mechanisms is the key to improve the operational safety, availability, and durability of ceramic components in many applications such as pumps in the chemical industry or power plants. Recently, a detailed investigation of the electrochemical corrosion of different $\mathrm{SiC}$ materials were carried out using potentiodynamic polarization measurements in acidic and alkaline environments [12-16]. They observed the formation of a thin layer of $\mathrm{SiO}_{2}$ on the surface in acid $(\mathrm{HCl}$, 
$\mathrm{HNO}_{3}$ ) and a more pronounced active corrosion in $\mathrm{NaOH}$. The electrochemical corrosion rate strongly depends on the specific electric resistance of the materials. With increasing specific electric resistance, the electrochemical reaction rate reduces. Beside this overall dependence, also deviation of the electrochemical reaction between different grains and even inside individual grains was found. In liquid phase-sintered materials (LPS SiC) and in silicon infiltrated materials ( $\mathrm{SiSiC}$ ), a core rime structure of the grains was observed with more pronounced corrosion at the rims [13, 16, 17]. This behavior is caused by the different doping levels of the core and rim resulting in different specific electric resistances and electrochemical corrosion. Additionally, the analysis of the corrosion rate of individual grains of a solid phase-sintered $\mathrm{SiC}$ material ( $\mathrm{SSiC}$ ) reveals that the corrosion rate of the individual grains show a large scattering $[14,15]$. This scattering could not be explained by different doping levels but only by the different grain boundary resistivities. Herrmann et al. [14] investigated the electrochemical corrosion of silicon carbide ceramics in sodium hydroxide at different potentials and found under anodic potential a specific recession of certain $\mathrm{SiC}$ grain surfaces, which correlated with the local resistivities.

In the past two decades, it has been reported in several works that the friction behavior of metal-metal and metalceramic contacts in surfactant-containing solutions can be actively influenced by the application of electrochemical potentials [18-21]. This mechanism was named potentialcontrolled friction (PCF) from Chang et al. [22] and Meng et al. [23]. However, most of these studies are focused on metals that have high electric conductivity. There have also been some investigations on the influence of electrochemical potentials on the tribological behavior of steel-ceramic sliding pairs [23, 24] and steel in contact with hard coatings (e.g., TiN-coatings [25]). In addition, it was shown that there is a clear influence of electrochemical potentials on the tribological and corrosion damage behavior of ceramic components in technical systems [26]. Potential-dependent changes in the coverage and stability of an adsorbed lubricating layer on a steel surface lead to different tribological behaviors [27]. Brandon et al. found the lowest wear at a electrochemical potential of $-1000 \mathrm{mV}$ against standard hydrogen electrode (SHE). A maximum wear was measured at anodic potentials due to the competing effects of oxidative corrosion and protective film formation. In addition, Kalin et al. [28] investigated how electrochemical parameters affect the properties of the surface layer, the physicochemical and load-carrying properties of the lubricating film. They showed that the wear of alumina and zirconia can be strongly affected by electrochemical parameters. It is suggested that the surface charge, the associated $\mathrm{pH}$ value and the zeta-potential influence the result of tribological tests. Due to the rolling of a cylinder, the charge distribution in the electric double layer (EDL), and also the friction force, changes [29].

In these tribological systems, which are influenced by electrochemical potentials, electrokinetic interactions between the sliding surfaces are suggested as important tribological mechanism [30]. Kelsall et al. [18] suggested that increased double-layer repulsion could reduce the friction coefficient and wear because the interfacial potential of a material surface is closely related to the tribological performance. Bai et al. [31] and other researchers [32, 33] noted that the electric double layer at very thin lubricating films lead to an electrokinetic effect by which the surface near viscosity is increased [34]. As consequence, hydrodynamic lubrication is partly ensured and the friction coefficient is reduced. A mathematical model of electro-viscosity is described by Zuo et al. [35]. They discussed the hydrodynamic and elastohydrodynamic water lubrication cases and showed that the apparent viscosity depends on the sum of two zeta potentials. Therefore, the electric double layer leads to an increase of the viscosity of very thin films. By analogy, Zhang and Umehara [36] and Chen et al. [37] suggested that the electric double layer generates a repulsive force and thus promotes hydrodynamic surface separation in sliding contacts. More details about the effect of the electric double layer on the friction properties were described by Kelsall et al. [18] and Zhu [38]. Electric double layer and boundary slip are coupled effects which influence the apparent viscosity and one-dimensional slide-bearing performance [39]. The electric double layer is influenced in the presence of electrochemical potentials and at high shear rates the charge movement in the diffuse layer causes a significant increase of the viscosity, which in consequence stabilizes hydrodynamic conditions [40].

As part of preliminary investigations of the authors, evidence was found that under certain electrochemical conditions friction, wear and corrosion performance can be significantly influenced by electrochemical potentials using electrically semiconductive ceramics [41, 42]. These preliminary investigations resulted in a patent for an apparatus and a method for operating a tribologically stressed component under the influence of electrochemical potentials [43]. But the fundamental understanding of the tribological behavior of $\mathrm{SiC}$ in aqueous solutions is still deficient, because of the complex interplay between mechanical, chemical, and electrochemical interactions during tribocorrosion [44]. In addition, the demand for higher energy efficiency of technical systems leads to increasing requirements for ceramic bearings. Therefore the aim of this work is to carry out a fundamental study to investigate the influence of electrochemical potentials on friction and wear. In particular, different electric conductive $\mathrm{SiC}$ materials were used to study the influence of electrochemical potentials on the tribological behavior. In 
addition, wear analysis was conducted after the friction tests to analyze the tribological mechanisms.

\section{Experimental}

\subsection{Electrochemical Characterization}

The electrochemical measurements of the $\mathrm{SiC}$ materials were conducted using three electrode setup. At first, the electrochemical window (ECW) was measured for $1 \mathrm{M}$ $\mathrm{NaCl}$-solution using cyclic voltammetry (CV) with a scan rate of $100 \mathrm{mV} / \mathrm{s}$. In addition, the open circuit potential (OCP) of the material was measured for $1000 \mathrm{~s}$ and subsequently the corrosion potential $\left(E_{\text {corr }}\right)$ was determined using linear scan voltammetry (LSV) with a scan rate of 1 $\mathrm{mV} / \mathrm{s}$. The measurements were performed using an $\mathrm{Ag} /$ $\mathrm{AgCl}-$ reference electrode, a platinum counter electrode and a pin as working electrode. The surface area of the pin was $116.2 \mathrm{~mm}^{2}$ and the measurements were carried out without rotation or loading. The LSV measurements were conducted immediately after immersion of the pins.

\subsection{Tribological Tests}

Tribological experiments were performed using a tribometer (TRM 1000, Wazau GmbH, Germany) with a rotating shaft on the upper side and a stationary setup fixed on the lower side. Two different geometries (Fig. 1) were used for the tribological tests: pin-on-disk and ring-on-disk. A three

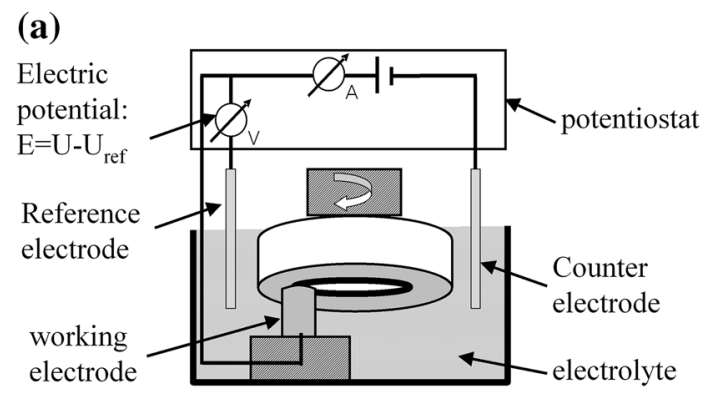

(b)

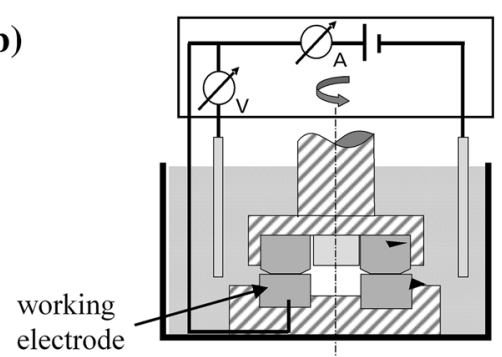

Fig. 1 Three electrode test setup for electrotribological measurements (WE: testing sample, $\mathrm{RE}: \mathrm{Ag} / \mathrm{AgCl}, \mathrm{CE}$ : platinum): a pin-ondisk geometry; b ring-on-disk geometry electrode test setup was used in which the stationary SiC material was set as working electrode. The pin-on-disk contact geometry was used to analyze the tribochemical effects and to select an appropriate material for the more application specific tests with the ring-on-disk geometry. The pin-on-disk tests were conducted at a load of $50 \mathrm{~N}$ which corresponds to an Hertzian contact pressure of $1 \mathrm{GPa}$. The initial point contact of the rounded pin-tip (radius: $5 \mathrm{~mm}$ ) changes during the tribological test to a surface contact due to wear. The applied electrochemical potentials were -1000 and $+500 \mathrm{mV}$ against $\mathrm{Ag} / \mathrm{AgCl}$. These electrochemical potentials were chosen to have a maximum and comparable cathodic and anodic potential related to OCP within the electrochemical stable window for a $1 \mathrm{M} \mathrm{NaCl}$-solution, because the adsorption and stability of a lubricating surface layer strongly depends on the electrochemical potential [27]. The ring-on-disk tests were carried out at loads of 100 and $200 \mathrm{~N}$ which corresponds to 0.2 and $0.4 \mathrm{MPa}$ contact pressure (contact area: $552 \mathrm{~mm}^{2}$ ), which was kept constant over the whole testing time. For each tribological test, new samples were used. The relative low sliding speeds of 0.1 and $0.2 \mathrm{~m} / \mathrm{s}$ were chosen to analyze friction and wear in the mixed lubrication regime, because the lubricant film thickness is mostly influenced by velocity besides the constant parameters viscosity and contact pressure. The film thickness at the used test parameters is calculated to appr. $0.2 \mu \mathrm{m}$ for pin-on-disk and appr. $8 \mu \mathrm{m}$ for ring-on-disk geometry [45]. It is described in literature that the transition from hydrodynamic to mixed lubrication takes place at a ratio of film thickness to composite surface roughness of 3 [46]. The roughness $\left(R_{a}\right)$ of the ceramics is between 5 and $10 \mu \mathrm{m}$ and so this ratio is much lower. To analyze the samples at higher anodic potentials, in relation to the $\mathrm{OCP}$, the electrochemical potentials were slightly modified to -800 and $+800 \mathrm{mV}$ against $\mathrm{Ag} / \mathrm{AgCl}$. In both test setups, the lower stationary sample was set as the working electrode. The counter body (disk or ring) was made of the same material as the pin. The electrochemical potential was measured between the working electrode (WE, testing sample: $\mathrm{SiC}$ ) and the reference electrode (RE: $\mathrm{Ag} / \mathrm{AgCl})$. The necessary current flow to maintain this potential was applied between the working electrode and the counter electrode (CE: platinum). The galvanic parameters were assessed before the test specimens were brought into contact. In a second step, the normal load was applied and the tribological test was started. In addition, it must be noticed that at tribological tests the counterbody gets in contact with the working electrode and so the electrochemically influenced area increases. The real surface area can be estimated to $700 \mathrm{~mm}^{2}$ at pin-on-disk and $2800 \mathrm{~mm}^{2}$ for ring-on-disk geometry.

Pin and disk were cleaned with ethyl alcohol before the test. The potential was controlled by a potentiostat 
(Wenking LPG03-50, Bank Elektronik GmbH). The medium (electrolyte) was $1 \mathrm{M} \mathrm{NaCl}$-solution, and all parts of the test setup were made of electrically isolating poly (methyl methacrylate) (PMMA).

The results of the wear analysis are explained in Sect. 3.3. After the tribological tests, the surfaces were analyzed using white light interferometry to measure the wear volume and evaluate the topography of the surface. To investigate deposits and wear debris (thin $\mathrm{SiO}_{2}$-layers) the Oxford Instruments thin film measurement tool [47, 48] was used [14]. With this tool surface layers between $1 \mathrm{~nm}$ and $1 \mu \mathrm{m}$ in thickness can be measured.

\subsection{Material}

Material characteristics of the $\mathrm{SiC}$ materials are listed in Table 1. It is noticeable that the material properties strongly depend on the composition and manufacturing route. The two $\mathrm{SSiC}$ materials are solid-state sintered materials that are electrically semiconductive due to their different amounts of $\mathrm{Al}-, \mathrm{N}-$, and $\mathrm{Si}$-dotation. $\mathrm{SiSiC}$ is a reactive sintered material formed by the infiltration of liquid $\mathrm{Si}$ into a $\mathrm{SiC}$-preform. During infiltration $\mathrm{Si}$ reacts with some residual carbon in the preform forming so-called secondary SiC. This secondary SiC exhibits usually higher conductivity due to impurity incorporations. The used SSiC-2 from ESK is also known as EKasicD. Figure 2 illustrates the surface of the different SiC-ceramics using field emission scanning electron microscope (FESEM). For the ring-on-disk friction tests, two different materials were selected Table 2. For sliding bearings and phase seals that are applied under severe conditions regarding tribological loads and corrosivity of the environment, crystalline diamond coatings have been developed [49-52]. Due to the chemical inertness of crystalline diamond-coated materials

Table 1 Material characteristics of the SiC materials for pin-on-disk tests

\begin{tabular}{llll}
\hline Characteristic & SSiC-1 & SiSiC & SSiC-2 \\
\hline Phases & SSiC & SiC/Si & SSiC \\
Supplier & FCT $^{\mathrm{a}}$ & H.C.S. & ESK $^{\mathrm{b}}$ \\
Additive types & $\mathrm{Al}, \mathrm{N}$ & - & $\mathrm{Al}$ \\
Elastic modulus $(\mathrm{GPa})$ & 406 & 343 & 440 \\
Spec. electr. res. $(\Omega \mathrm{cm})$ & 400 & 0.01 & 250 \\
Vickers hardness $(\mathrm{HV})$ & 3030 & 2716 & 2946 \\
Roughness $(\mu \mathrm{m})$ & & & \\
$\quad \mathrm{R}_{\mathrm{a}}$ & 13.7 & 5.20 & 10.2 \\
$\mathrm{R}_{\mathrm{z}}$ & 149.6 & 142.70 & 96.1 \\
\hline
\end{tabular}

${ }^{a}$ FCT Hartbearbeitungs GmbH, Sonneberg, Germany

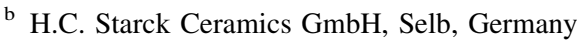

${ }^{c}$ Former ESK Ceramics GmbH now 3M Technical Ceramics
[53], tribochemical reactions on the surface can be excluded during the friction test.

\section{Results}

\subsection{Electrochemical Characterization}

The used $1 \mathrm{M} \mathrm{NaCl-solution} \mathrm{(} \mathrm{pH} \mathrm{7.1,} \mathrm{deionized} \mathrm{water)}$ shows no chemical reaction (no oxygen or hydrogen formation) between -1 and $+1 \mathrm{~V}$ against SHE, which was measured using cyclic voltammetry (Fig. 3a). But it must be noticed that the solution is not buffered and therefore the $\mathrm{pH}$ value can change during the tribological test due to effects of dissolved air $\left(\mathrm{CO}_{2}\right)$. The change of the $\mathrm{pH}$ value also influences the area in which water is electrochemically stable (Pourbaix diagram). In Fig. 3b the open circuit potential (OCP) of SSiC-1, SSiC-2, and SiSiC over $1000 \mathrm{~s}$ is illustrated. In contrast to $\mathrm{SSiC}-1$ and $\mathrm{SSiC}-2, \mathrm{SiSiC}$ has a significantly lower OCP and and a stronger scatter of the measured values. But after $1000 \mathrm{~s}$, the OCP is also stable for SSiC-2 and SiSiC. Figure 3c shows the result of the linear scan voltammetry (LSV) of the three materials. In accordance with the OCP measurement, $\mathrm{SiSiC}$ has also a lower corrosion potential $\left(E_{\text {corr }}\right)$ than the other two materials. SSiC2 has a lower corrosion current density $\left(i_{\text {corr }}\right)$ than SSiC-1 and SiSiC, which nearly show similar values (Table 3). For the calculation of the degree of corrosion per year $m_{y}$ (Eq. 1, in $\mathrm{g} / \mathrm{cm}^{2}$ per year) the measured corrosion current density $\left(i_{\text {corr }}\right.$ in $\mathrm{A})$, the molar mass ( $M$ in mol), the number of electrons which participate at the chemical reaction $(z)$, the Faraday constant $(F$ in $\mathrm{A} / \mathrm{mol})$ and the time $(t=1$ year in $\mathrm{s})$ are needed. This value can be converted by using the material density $\left(\mathrm{g} / \mathrm{cm}^{3}\right)$ to the corrosion rate in $\mu \mathrm{m} / \mathrm{y}$ (Table 3). As a result of the different corrosion current densities, SSiC-2 has the lowest corrosion rate. In addition the anodic and cathodic Tafel slopes $\left(\beta_{\mathrm{a}}\right.$ and $\left.\beta_{\mathrm{c}}\right)$ were calculated from the experimental data (Table 3 ). $\beta_{\mathrm{c}}$ is related to the kinetics of the corrosion reaction and is generally about $120 \mathrm{mV}$ for the cathodic reactions of hydrogen ion reduction or oxygen reduction [54, 55]. The three materials show comparable values for $\beta_{\mathrm{c}}$. In contrast to $\mathrm{SiSiC}$, the two ceramics without $\mathrm{Si}$ (SSiC-1 and SSiC-2) have a distinct higher $\beta_{\mathrm{a}}$, which implies passivity [56].

$m_{\mathrm{y}}=\frac{M i_{\text {corr }} t}{z F}$

\subsection{Pin-on-Disk Tests}

Figure 4 shows the coefficient of friction against time under the influence of potential steps. The three 


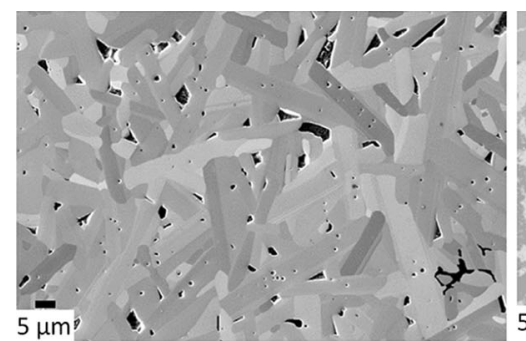

SSiC-1

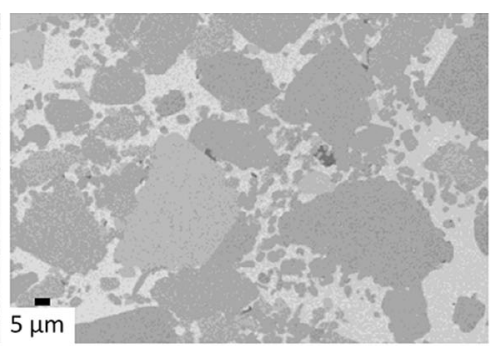

SiSiC

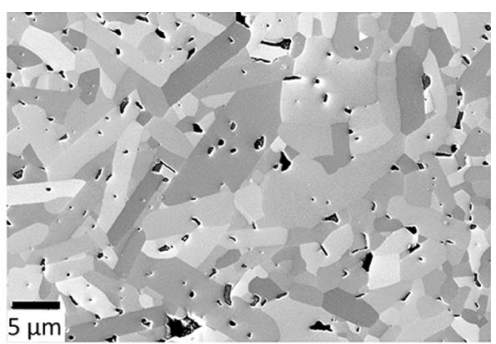

SSiC-2

Fig. 2 Surface analysis of the SiC-ceramics using field emission scanning electron microscope (FESEM)

Table 2 Material characteristics of the $\mathrm{SiC}$ materials for ring-on-disk tests

\begin{tabular}{|c|c|c|c|c|}
\hline \multirow[t]{2}{*}{ Characteristic } & \multicolumn{2}{|c|}{$\mathrm{SSiC}-3$} & \multicolumn{2}{|c|}{ Diamond-coated } \\
\hline & Ring & Disk & Ring & Disk \\
\hline Supplier & \multicolumn{2}{|c|}{ EagleBurgmann $^{\mathrm{a}}$} & \multicolumn{2}{|c|}{ EagleBurgmann $^{\mathrm{b}}$} \\
\hline Electric resistance & $7 \mathrm{k} \Omega$ & $\mathrm{M} \Omega$-range & $0.05 \mathrm{k} \Omega$ & $5 \mathrm{k} \Omega$ \\
\hline
\end{tabular}

${ }^{a}$ EagleBurgmann Germany GmbH, Wolfratshausen

b Coated at Fraunhofer IST

tribological tests with $\mathrm{SSiC}-1, \mathrm{SiSiC}$, and $\mathrm{SSiC}-2$ started at OCP (without any external potential) and after approximately $15 \mathrm{~min}$ a cathodic potential was applied. SSiC-1 shows a decrease of friction over the whole testing time, but no response to cathodic or anodic potentials (Fig. 4a). In contrast, the coefficient of friction (COF) of $\mathrm{SiSiC}$ and SSiC-2 are directly affected by potential change (Fig. 4b, c). For both materials, the cathodic potential $(-1000 \mathrm{mV}$ vs. $\mathrm{Ag} / \mathrm{AgCl})$ causes a decrease $(\approx-8 \%)$ and an anodic potential an increase $(\approx+4 \%)$ of the $\mathrm{COF}$.

In addition, sliding speed and normal force were varied to further evaluate the influence of the tribological conditions. Figure 5 shows an overview of friction coefficients with pin-on-disk geometry using $1 \mathrm{M} \mathrm{NaCl}$ at different testing parameters for SiSiC. The influence of the electrochemical potentials on the $\mathrm{COF}$ of $\mathrm{SiSiC}$ strongly depends on the tribological parameters. At low sliding speed, the effect is more significant than at higher speeds. The normal force has only little influence on the COF at these parameters.

Figure 6 shows the $\mathrm{COF}$ of $\mathrm{SSiC}-1$ over $2 \mathrm{~h}$ at a constant potential. As measured at potential steps (Fig. 4a), SSiC-1 shows also a decreasing COF over the whole testing time without external electrochemical potential (Fig. 6a). Using cathodic potential, there is nearly no difference in the $\mathrm{COF}$ to the result at OCP. At anodic potential, the decrease of COF is lower and ends at higher values in contrast to OCP and cathodic potential (Fig. 6b). The current of the tests at anodic and cathodic potentials is plotted in Fig. 6c. Both curves tend to a constant current value after a short time. But at the cathodic potential, the current approaches approximately 0 $\mu \mathrm{A}$, whereas at $+500 \mathrm{mV}$ versus $\mathrm{Ag} / \mathrm{AgCl}$ a higher current of $+25 \mu \mathrm{A}$ is observed over the whole testing time. This is consistent with the voltammograms. At $-1000 \mathrm{mV}$ versus $\mathrm{Ag} / \mathrm{AgCl}$ oxidation of solved oxygen and may be a slight water decomposition takes place, whereas at $+500 \mathrm{mV}$ versus $\mathrm{Ag} / \mathrm{AgCl}$ the permanent oxidation of $\mathrm{SiC}$ and the formation of a $\mathrm{SiO}_{2}$ surface layer is observed.

The results of the tribological tests using $\mathrm{SiSiC}$ at constant potentials are shown in Fig. 7. The COF values are quite constant over the whole testing time. In accordance with SSiC-1, the current tends to a constant value after a short time. The current at anodic potential is at $+75 \mu \mathrm{A}$ and for cathodic potential at $-70 \mu \mathrm{A}$ and therefore obviously higher than for SSiC-1 in both cases.

To evaluate the current flow the necessary electric charge transfer $Q$, to maintain the different potentials, was calculated using Eq. 2:

$$
Q=\int_{t=0}^{t=\text { end }} I \cdot \mathrm{d} t
$$

The calculated values for the electric charge transfer $Q$ are listed in Table 4. SSiC-1 has considerably lower values than $\mathrm{SiSiC}$. For cathodic potential, lower values are measured for both materials.

An overview on the $\mathrm{COF}$ at the end of the tribological tests at constant potentials is shown in Fig. 8. In Table 4, the measured change of the COF and wear of SSiC-1 and SiSiC using potentials with pin-on-disk geometry are compared. The COF of SSiC-1 doubles at anodic potential compared to the test without potential. At cathodic potential, the COF is not different from the $\mathrm{COF}$ at OCP. For $\mathrm{SiSiC}$, a clear improvement of the $\mathrm{COF}$ at cathodic potential and also a little decrease at anodic potential is observable.

\subsection{Wear Analysis}

After the pin-on-disk-tests at constant electrochemical potential, the wear tracks of the disks were analyzed using white light interferometry (Fig. 9). The wear on the disk was measured over a length of $5 \mathrm{~mm}$, and then extrapolated 

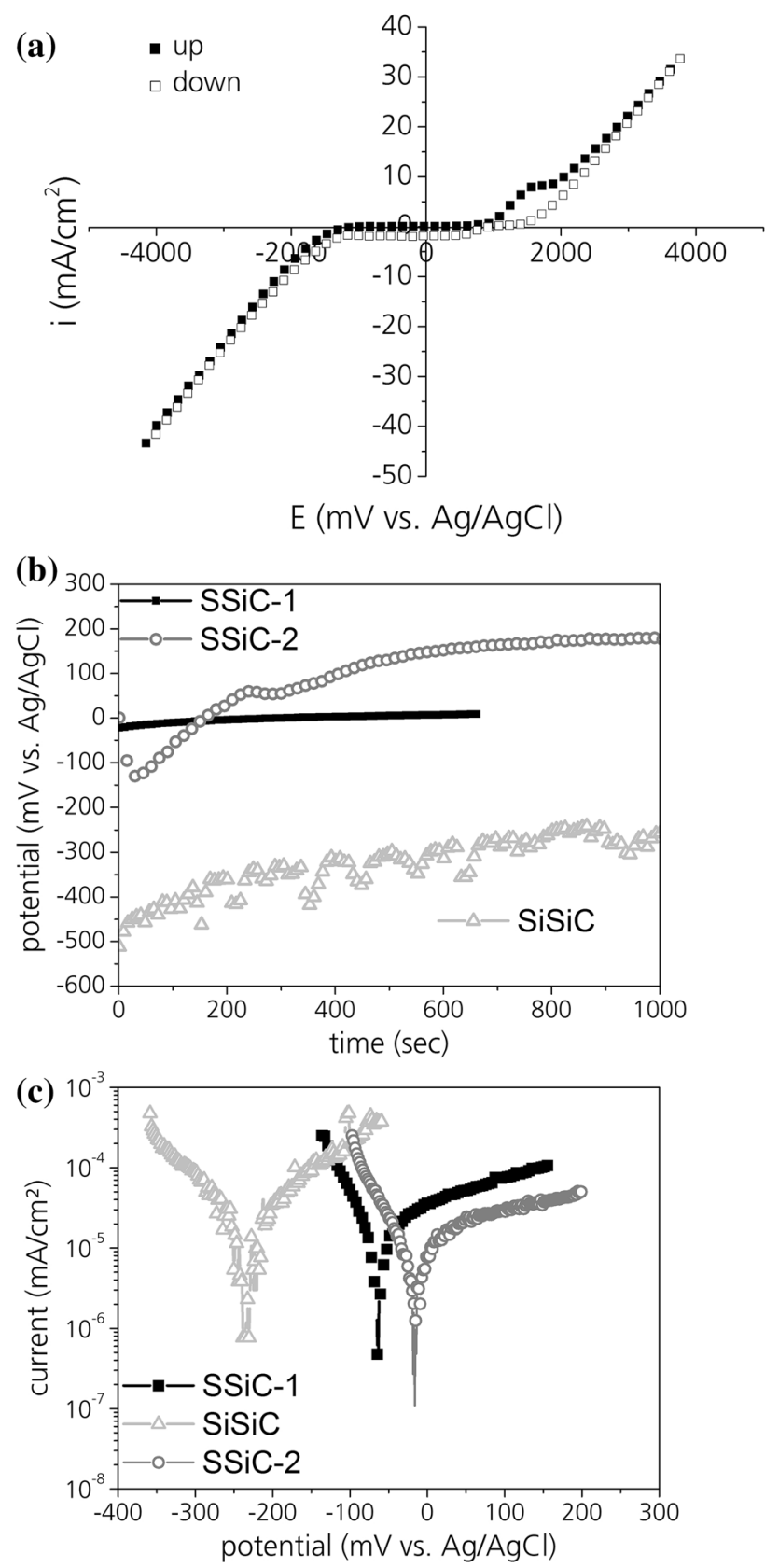

Fig. 3 Electrochemical characterization of SSiC-1-, SSiC-2-, and SiSiC-pins in $1 \mathrm{M} \mathrm{NaCl}$-solution: a result of cyclic voltammetry for a $1 \mathrm{M} \mathrm{NaCl}$-solution; b open circuit potential (OCP) over time; c measurement of the corrosion potential with linear scan voltammetry (LSV, scan rate: $1 \mathrm{mV} / \mathrm{s})$

to the whole wear scar length of $88 \mathrm{~mm}$. Both materials show grooves in sliding direction on the worn surface.

The wear measurement of pin (Fig. 10a) and disk show that the wear is lower when a cathodic potential is applied (Fig. 10b). The wear volume of the disks was lower than the wear of the pins. This difference may be caused by the different contact conditions: since the pin surfaces are in permanent contact throughout the whole test, the pin
Table 3 Results of the electrochemical characterization

\begin{tabular}{llll}
\hline Parameter & SSiC-1 & SiSiC & SSiC-2 \\
\hline$E_{\text {corr }}(\mathrm{mV}$ versus Ag/AgCl $)$ & -65 & -234 & -18 \\
$i_{\text {corr }}\left(\mathrm{nA} / \mathrm{cm}^{2}\right)$ & 24.1 & 25.9 & 15.5 \\
$\beta_{\mathrm{c}}(\mathrm{mV} /$ decade of current $)$ & 70 & 120 & 79 \\
$\beta_{\mathrm{a}}(\mathrm{mV} /$ decade of current $)$ & 338 & 146 & 524 \\
Corrosion rate $(\mu \mathrm{m} /$ year $)$ & 45 & 52 & 30 \\
\hline
\end{tabular}

temperature may be slightly higher and therefore the tribochemical reactivity of the surface slightly enhanced. Anodic potential leads to a significantly higher wear compared to reference tests at OCP. In agreement to the COF results, the influence of electrochemical potentials on wear is stronger for $\mathrm{SSiC}-1$ that for $\mathrm{SiSiC}$. The most pronounced difference was observed for $\mathrm{SSiC}-1$ at anodic potential. Here, the wear volume of the ring was almost $170 \%$ higher (Table 5).

The deposits and wear debris of the worn pins after tribological tests at different electrochemical potentials were studied using SEM-EDS (Fig. 11). SSiC-1 shows a smoothing of the surface with some grooves without cracks and typical pores at all three test conditions. The main difference is some $\mathrm{SiO}_{2}$ debris, which were observed at anodic potential (Fig. 11a). For SiSiC without potential, cracks occured in the $\mathrm{SiC}$ (darker ares) perpendicular to the rubbing direction. On the silicon (brighter ares), there are some grooves (Fig. 11b). At cathodic and anodic potential, there are also partially cracks in the silicon (Fig. 11c) in contrast to OCP.

\subsection{Ring-on-Disk Tests}

Friction tests with at different electrochemical potentials were started at OCP, afterward the potential was changed as shown in Fig. 12a, b. The friction values of SSiC-3 at OCP (SSiC) show that the friction coefficient reached constant value of 0.11 after a 30 min running-in period. In contrast to the subsequent cathodic polarization with nearly no change in $\mathrm{COF}$, there is a strong COF change at anodic potential (Fig. 12a). This increase of the COF is reversible because after switching the potential to OCP the $\mathrm{COF}$ decreases to its starting level after running-in.

The influence of electrochemical potential steps on the $\mathrm{COF}$ with ring-on-disk geometry using diamond-coated $\mathrm{SiC}$ is shown in Fig. 12b, c. It was observed that the friction coefficient decreases strongly at cathodic polarization and increases at anodic polarization (Fig. 12b). During the OCP steps, the friction coefficient returned to the initially higher values. Figure $12 \mathrm{c}$ gives an overview on the friction behavior of diamond-coated $\mathrm{SSiC}$ at different electrochemical potentials and tribological loads. It is clearly 

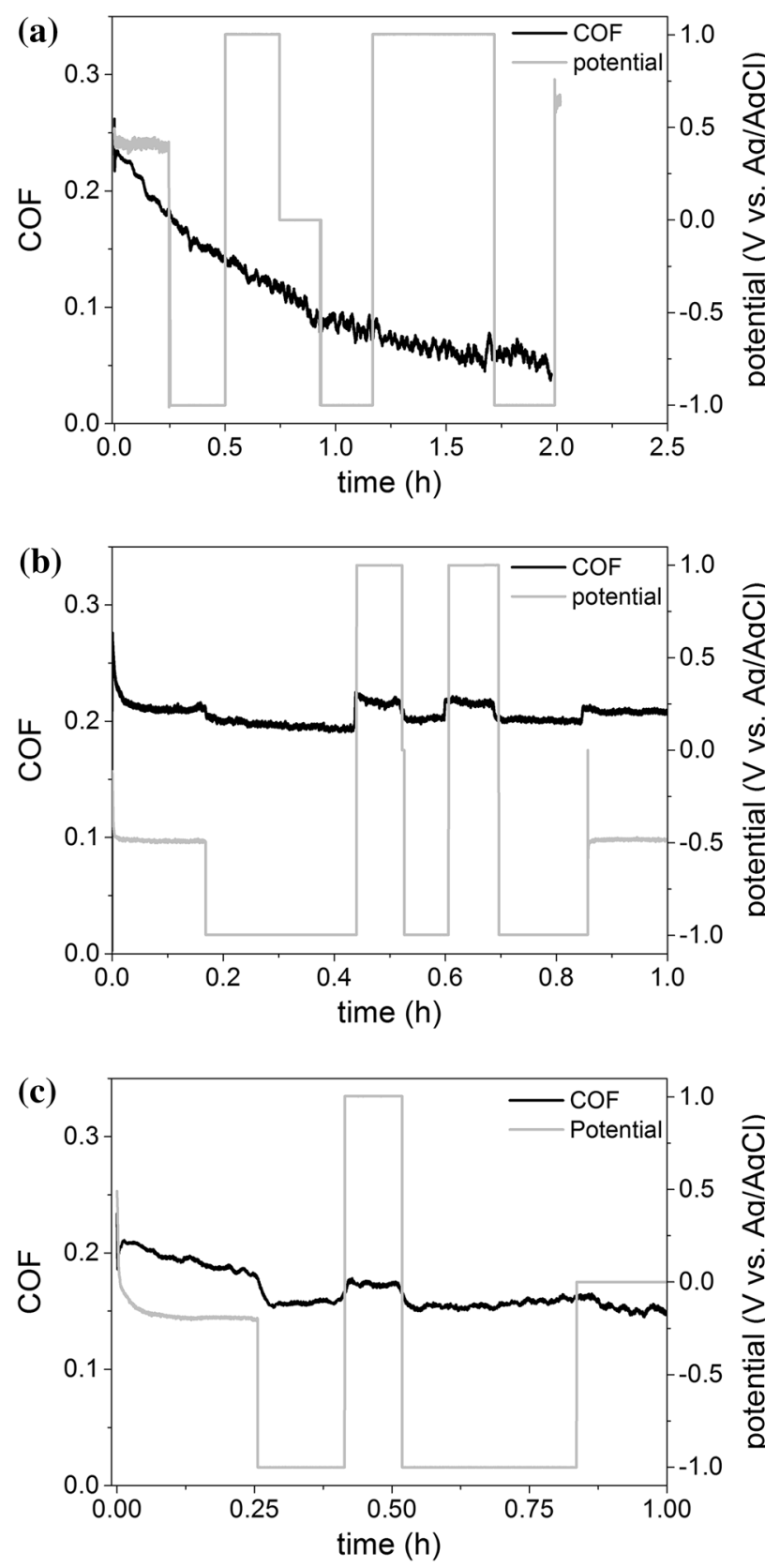

Fig. 4 Friction coefficients at different electrochemical potentials that were manually switched to different values $(-1000,+1000$, $-1000,0 \mathrm{mV}$ vs. $\mathrm{Ag} / \mathrm{AgCl})$ using pin-on-disk geometry $(1 \mathrm{~mol} \mathrm{NaCl}$, $50 \mathrm{~N} ; 0.1 \mathrm{~m} / \mathrm{s}$ ): a SSiC-1; b SiSiC; c SSiC-2

visible that the influence of the electrochemical potential on the $\mathrm{COF}$ is stronger at higher loads and lower sliding velocities, which implies that under mixed lubrication conditions (i.e., very thin lubrication films and partially solidsolid contact), the electrochemical influence is stronger. The strongest effect was observed at $0.2 \mathrm{~m} / \mathrm{s}$ and $200 \mathrm{~N}$, which was the highest applied load within this test series. At these parameters, the COF is reduced by $-35 \%$ under cathodic polarization and increased by $+45 \%$ using anodic polarization.

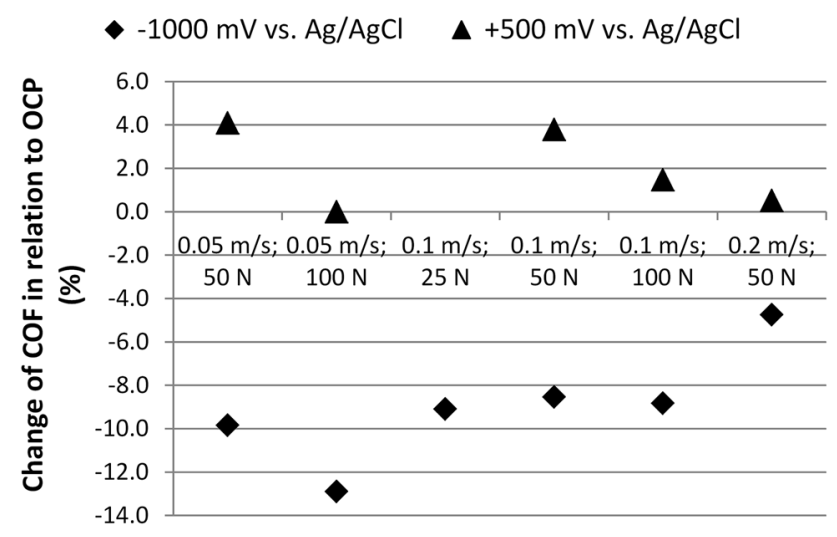

Fig. 5 Change of the coefficient of friction of $\mathrm{SiSiC}$ at different electrochemical potentials and test parameters in relation to OCP

Tribological tests with SSiC-3 at constant electrochemical potentials were performed (Fig. 13). The tests were conducted in three $20 \mathrm{~h}$ steps. After each step, the test was stopped and the load was removed. Without electrochemical potential, the COF started at about 0.5 and dropped to about 0.1 after 10 hours. In the second step, the COF increased slightly and in the third step the COF was rather constant at a value of 0.13 . At cathodic potential, the test started at a COF of about 0.4 and decreased already after $3 \mathrm{~h}$ to 0.1 . During the second and third step, a very constant $\mathrm{COF}$ was achieved. The $\mathrm{COF}$ after $60 \mathrm{~h}$ was significantly lower than the COF at OCP. At anodic polarization, the test started with a COF of 0.6 and decreases after $4 \mathrm{~h}$ also to a value of 0.1 , which was stable until the end of the test.

\section{Discussion}

In previous publications, several tribological mechanisms for water-lubricated $\mathrm{SiC}$ sliding contacts have been proposed [5, 7, 10, 11, 30, 32, 57, 58]. Most of them identified tribochemical reactions as a clue for the explanation of low and stable friction coefficients. The mild chemical wear may lead to the formation of very smooth surfaces and tribochemical oxidation products may act as lubricious oxides. Only few papers recognized electrochemical effects, especially electrokinetic effects a possible mechanism to significantly influence friction and wear [34, 41, 42]. As shown in this work, electrochemical potentials strongly influence the tribological behavior. Therefore the formation of an electric double layer (EDL), which consists of a compact layer (ions are strongly attracted to the wall surface and are immobile) and a diffuse double layer (ions are affected less by the electrical field and are mobile), is assumed to initiate the changed tribological behavior using electrochemical potentials. An EDL is formed on a solid 

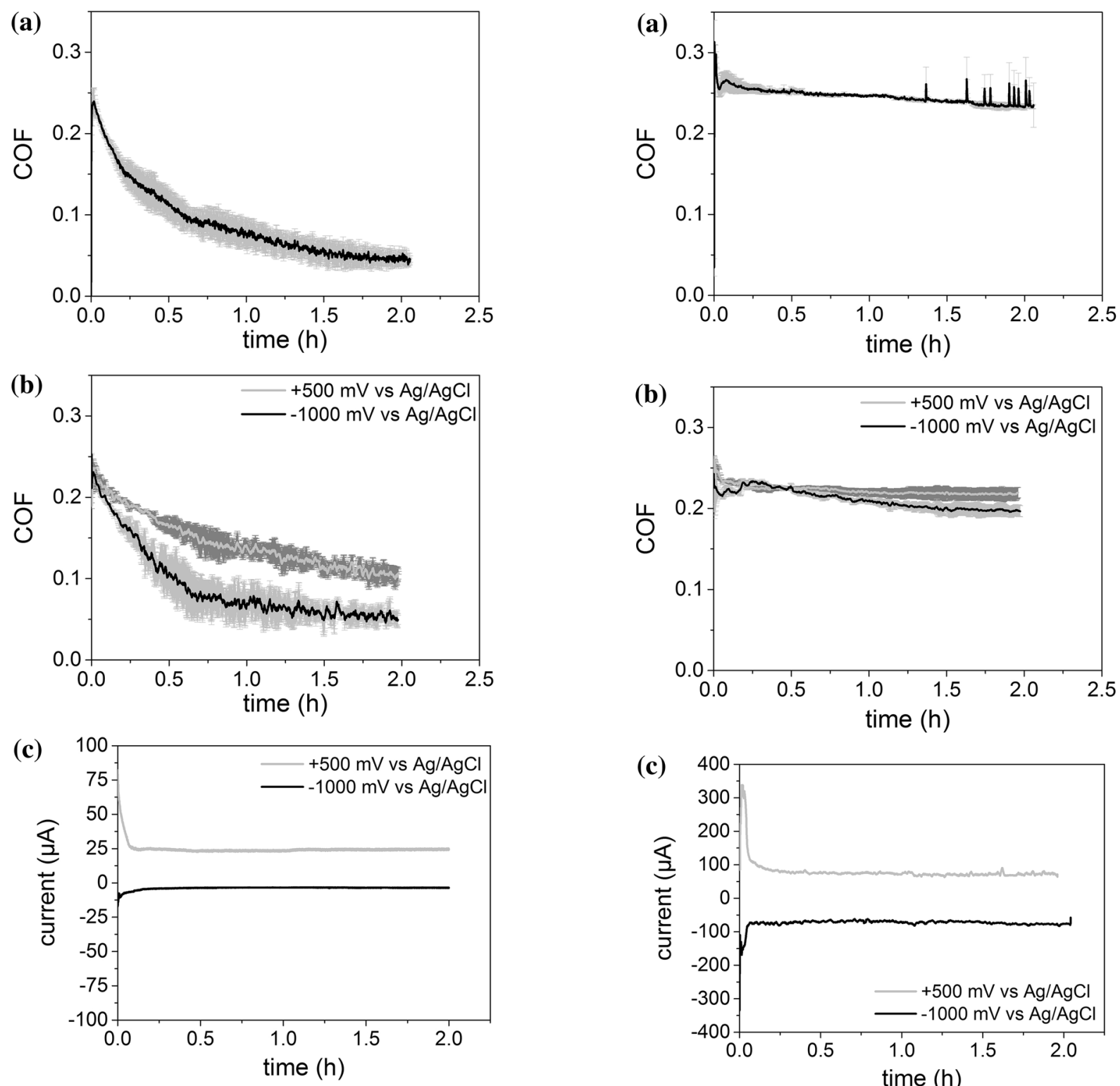

Fig. 6 Results of the friction tests at a constant electrochemical potential with pin-on-disk geometry using SSiC-1 (1 M NaCl, $50 \mathrm{~N}$; $0.1 \mathrm{~m} / \mathrm{s}, 2 \mathrm{~h}$ ): a at OCP without external potential; b at cathodic and anodic potential; c current measured during friction test at cathodic and anodic potential

surface due to an electrochemical potential. The thickness of the diffuse EDL depends upon the electric potential of the solid surface. The electrical potential at the boundary between the compact layer and the diffuse layer is called the zeta potential. In addition, shear of EDL leads to a movement of the ions in the mobile part of the EDL and this causes an electrical current (streaming current) and this sets up an electrical field which leads to an electrical potential, the streaming potential [59]. This electrokinetic effect $[18,38,40]$ then leads to an increase of the surface near viscosity and causes an increase of the electrostatic

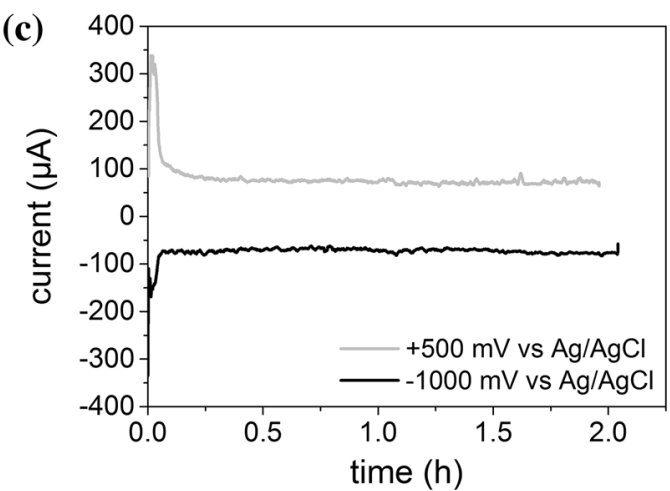

Fig. 7 Coefficient of friction at a constant electrochemical potential using pin-on-disk geometry (SiSiC; $1 \mathrm{M} \mathrm{NaCl}, 50 \mathrm{~N} ; 0.1 \mathrm{~m} / \mathrm{s}, 2 \mathrm{~h}$ ): a test at OCP without external potential; $\mathbf{b}$ test at cathodic and anodic potentials; c current measured during friction test at cathodic and anodic potential

Table 4 Electric charge transfer $Q$ and change of the COF due to electrochemical potentials in relation to OCP using pin-on-disk geometry

\begin{tabular}{llll}
\hline Material & el. potential & $\mathrm{COF}(\%)$ & $Q$ \\
\hline SSiC-1 & $-1000 \mathrm{mV}$ versus $\mathrm{Ag} / \mathrm{AgCl}$ & +6 & $0.027 \mathrm{C}$ \\
& $+500 \mathrm{mV}$ versus $\mathrm{Ag} / \mathrm{AgCl}$ & +120 & $0.179 \mathrm{C}$ \\
SiSiC & $-1000 \mathrm{mV}$ versus $\mathrm{Ag} / \mathrm{AgCl}$ & -15 & $0.543 \mathrm{C}$ \\
& $+500 \mathrm{mV}$ versus $\mathrm{Ag} / \mathrm{AgCl}$ & -6 & $0.567 \mathrm{C}$ \\
\hline
\end{tabular}




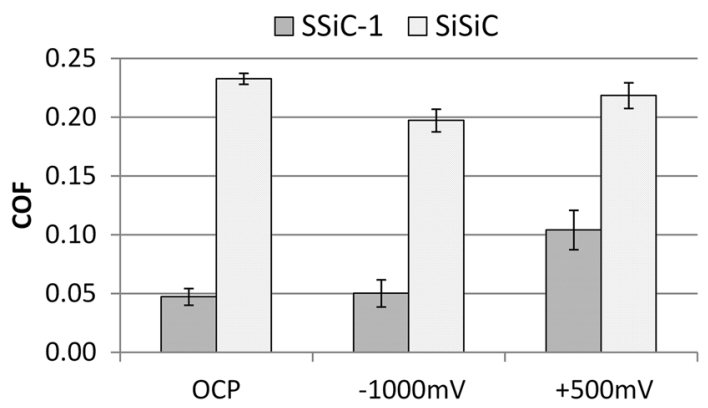

Fig. 8 Comparison of the final friction coefficients at constant electrical potentials from Figs. 4 and 6

repulsion, especially at a very thin lubricating film $[18,31-$ 34]. These mechanisms support the hydrodynamic lubrication, which can be observed due to the change of the coefficient of friction using electrochemical potentials. In addition, it can be assumed that the effect of EDL is the most important mechanism concerning the change of the tribological behavior, because there is also a very strong influence of electrochemical potentials visible by using diamond-coated surfaces at which tribochemical reactions on the surface can be excluded (Fig. 12).

The results of this investigation but also show that $\mathrm{SiC}$ materials of different material compositions show significantly different results in both sliding geometries (i.e., pinon disk and ring-on ring). This can be mostly explained by different electrical conductivities of the ceramics. The grain boundaries in $\mathrm{SiC}$ materials have an higher electrical resistivity in comparison to the grains [17, 60-62]. Therefore the current through the grain and thus the value of corrosion will be different for different grains due to the distribution of grain boundary resistivities [14]. Because of this electric behavior not only the electric conductivity of the whole test specimen is relevant, but also the microscale variation of the conductivity due to microstructural effects. As shown by Herrmann et al. [14] these local variations of electric conductivities lead to locally different (a)

SSiC-1 SiSiC
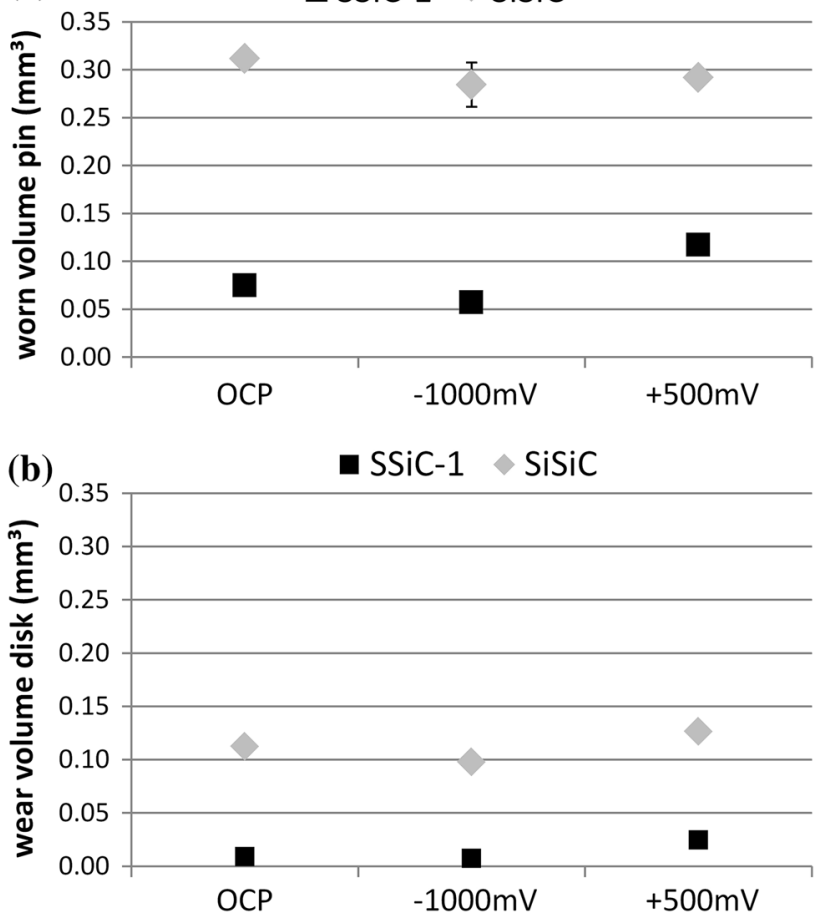

Fig. 10 Wear analysis of pin-on-disk ( $1 \mathrm{M} \mathrm{NaCl}, 50 \mathrm{~N} ; 0.1 \mathrm{~m} / \mathrm{s} ; 2 \mathrm{~h})$ : a wear volume of the pin; $\mathbf{b}$ wear volume of the disk

Table 5 Change of wear due to electrochemical potentials in relation to OCP using pin-on-disk geometry

\begin{tabular}{llll}
\hline Material & El. potential & \multicolumn{2}{l}{ Wear volume } \\
\cline { 3 - 4 } & & Disk (\%) & Pin (\%) \\
\hline \multirow{2}{*}{$\mathrm{SSiC}-1$} & $-1000 \mathrm{mV}$ versus $\mathrm{Ag} / \mathrm{AgCl}$ & -17 & -21 \\
& $+500 \mathrm{mV}$ versus $\mathrm{Ag} / \mathrm{AgCl}$ & +171 & +45 \\
$\mathrm{SiSiC}$ & $-1000 \mathrm{mV}$ versus $\mathrm{Ag} / \mathrm{AgCl}$ & -13 & -14 \\
& $+500 \mathrm{mV}$ versus $\mathrm{Ag} / \mathrm{AgCl}$ & +12 & -7 \\
\hline
\end{tabular}

Fig. 9 Analysis of the wear scar of the disk after pin-on-disk test with constant electrochemical potential using white light interferometry $(1 \mathrm{M} \mathrm{NaCl}, 50 \mathrm{~N}$; $0.1 \mathrm{~m} / \mathrm{s} ; 2 \mathrm{~h}$ ): (above) $\mathrm{SSiC}-1$; (below) $\mathrm{SiSiC}$
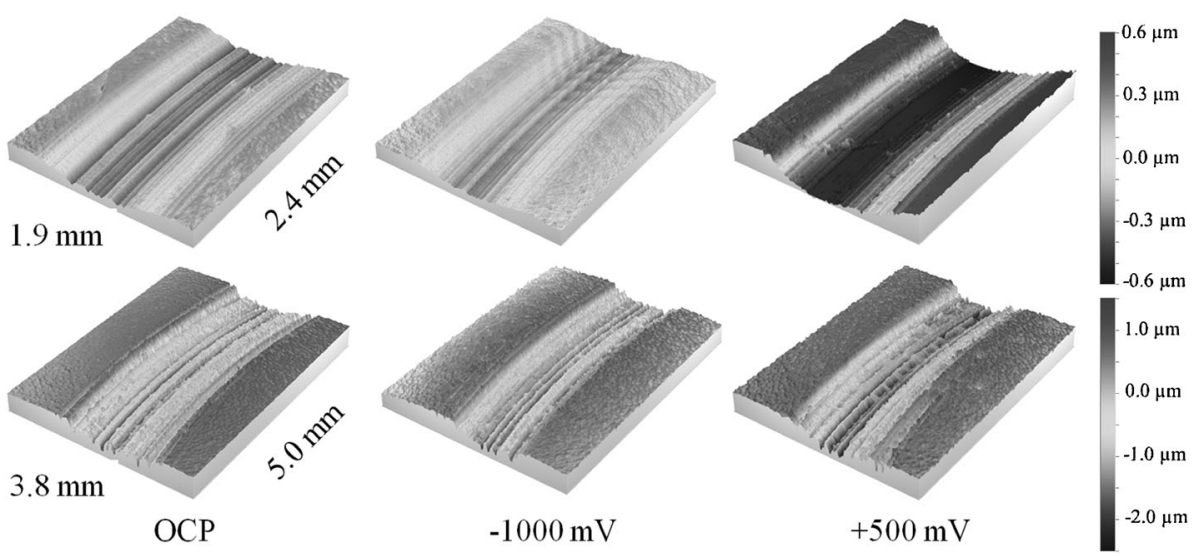


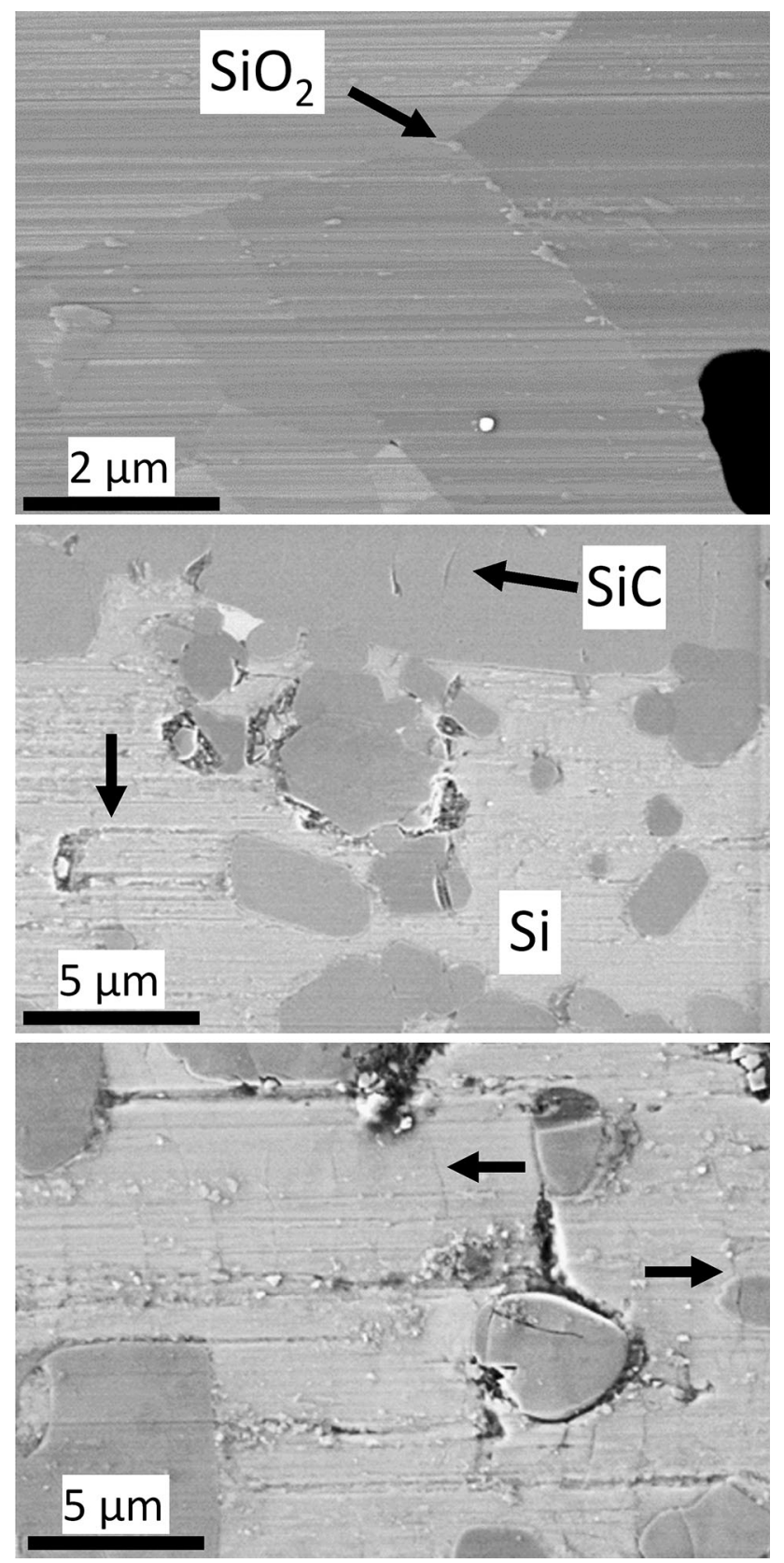

Fig. 11 Analysis of the wear scar of the pins after pin-on-disk friction test with scanning electron microscope $(1 \mathrm{M} \mathrm{NaCl}, 50 \mathrm{~N} ; 0.1 \mathrm{~m} / \mathrm{s} ; 2$ h): a SSiC-1 $(+500 \mathrm{mV}$ vs. $\mathrm{Ag} / \mathrm{AgCl}): \mathrm{SiO}_{2}$ debris besides a smooth wear surface; $\mathbf{b} \mathrm{SiSiC}(\mathrm{OCP})$ : cracks in the $\mathrm{SiC}$ and grinding marks on the silicon; c $\mathrm{SiSiC}(-1000 \mathrm{mV}$ vs. $\mathrm{Ag} / \mathrm{AgCl})$ : also partially cracks in the silicon

electrochemical corrosion rates. But it can also be assumed that electric double layers can only be influenced by electrochemical potentials when the electric activity of the surface is sufficiently high. The formation of a $\mathrm{SiO}_{2}$ surface layer was provided after electrochemical corrosion exper-
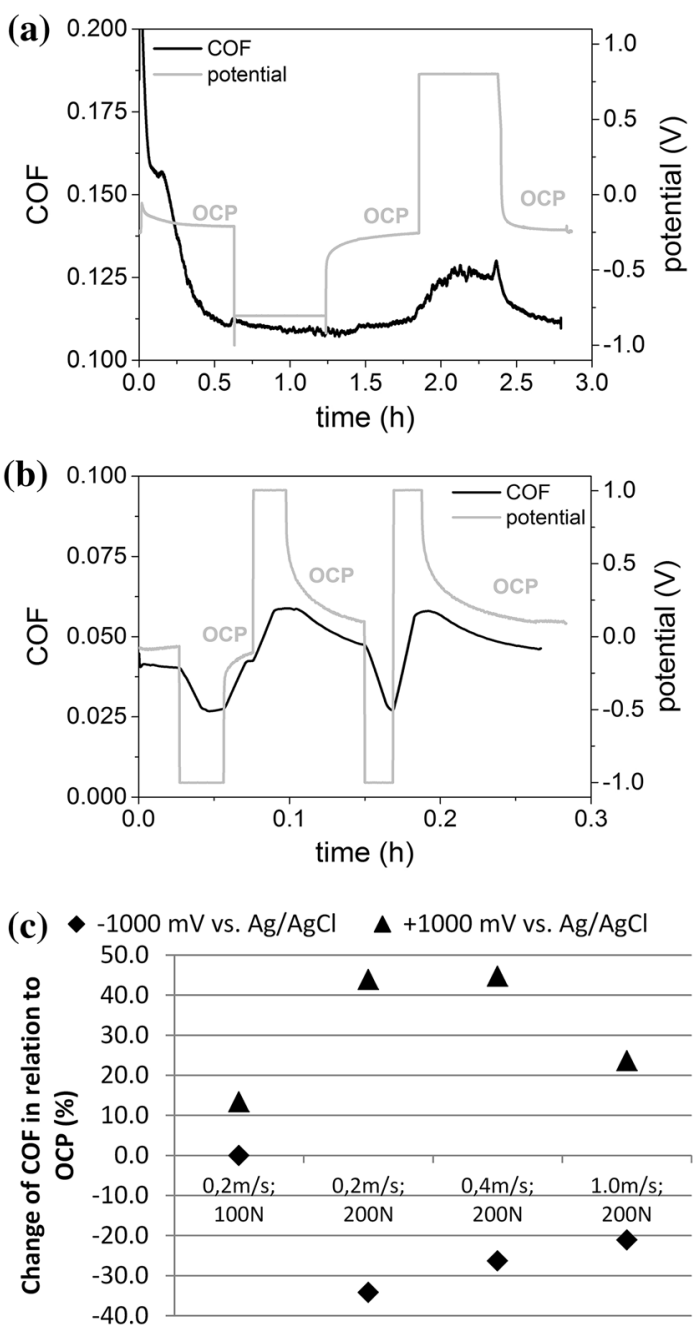

Fig. 12 Influence of electrochemical potential on the coefficient of friction using ring-on-disk geometry $(1 \mathrm{M} \mathrm{NaCl})$ : a SSiC-3 $(100 \mathrm{~N}$; $0.2 \mathrm{~m} / \mathrm{s}) ;$ b diamond-coated $\mathrm{SSiC}(200 \mathrm{~N} ; 0.2 \mathrm{~m} / \mathrm{s})$; c COF under various tribological test conditions for diamond-coated SSiC

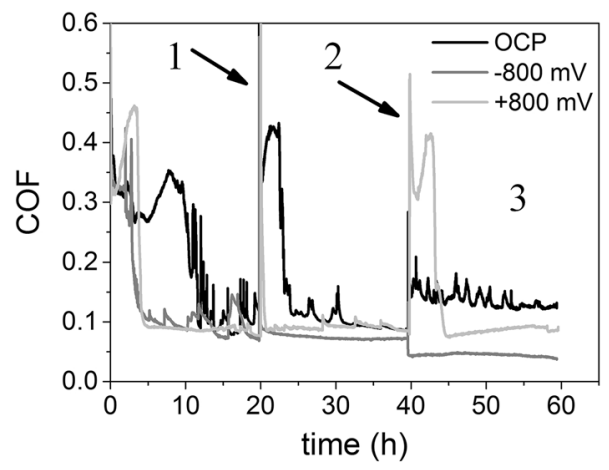

Fig. 13 Results of friction tests using ring-on-disk geometry (1 M $\mathrm{NaCl} ; 100 \mathrm{~N} ; 0.2 \mathrm{~m} / \mathrm{s}$ ): $\mathrm{COF}$ of $\mathrm{SSiC}-3$ at three successive $20 \mathrm{~h}$ friction tests at a constant electrochemical potential 
iments of $\mathrm{SSiC}$ in $\mathrm{H}_{2} \mathrm{SO}_{4}$ at different voltages [14]. The grains for which the grain boundary resistivity is low will exhibit a high current density and therefore form thicker $\mathrm{SiO}_{2}$ layers [14]. Therefore the formation of an $\mathrm{SiO}_{2}$ surface layer under electrochemical potentials could have a dominating influence concerning the friction behavior.

Discussing the effect of the electrical potential two cases have to be distinguished the anodic and cathodic polarization. In the anodic range, the oxidation of the SiC surface takes place:

$\mathrm{SiC}+4 \mathrm{H}_{2} \mathrm{O} \rightleftharpoons \mathrm{SiO}_{2}+8 \mathrm{H}^{+}+\mathrm{CO}_{2}+8 \mathrm{e}^{-}$

$\mathrm{SiC}$ materials with different compositions and microstructures exhibit different corrosion behaviors. It is noticeable that the corrosion rate of $\mathrm{SiC}$ strongly depends on the specific electric resistance [14]. This is in good agreement with our results on $\mathrm{SiSiC}$ which has, due to the low electric resistance, the highest corrosion current density and therefore the highest corrosion rate. But there could be also strong local variations of the anodic corrosion behavior of $\mathrm{SiC}$ that correlate with the local electric conductivity of the material. Herrmann et al. [14] showed that domains of low electric conductivity show less chemical attack. As previous experiments have shown [16], in the SiSiC material the most intensive electrochemical corrosion takes place at the rims of the $\mathrm{SiC}$ grains. Si and the core of the $\mathrm{SiC}$ grains are less attacked. This is on the one hand caused by the different local resistivities due to different doping levels of the core and the rim of the $\mathrm{SiC}$. On the other hand, the structure of the $\mathrm{SiO}_{2}$ layer on $\mathrm{Si}$ and $\mathrm{SiC}$ seems to be different. On the $\mathrm{Si}$ very thin passivating layers (up to $5 \mathrm{~nm}$ ) were found, whereas on the $\mathrm{SiC}$ the thickness of the electrochemical formed $\mathrm{SiO}_{2}$ layers can reach up to $100 \mathrm{~nm}$ under the same conditions $[14,16]$. The consequence is that in the $\mathrm{SiSiC}$ material only a small fraction of the surface is affected by the electrical potential. Therefore, the influence of the potential on the tribological behavior is much less pronounced for $\mathrm{SiSiC}$-ceramics in comparison to the $\mathrm{SSiC}$ materials investigated despite the fact that the $\mathrm{SiSiC}$ material has a lower resistivity in comparison to the investigated $\mathrm{SSiC}$ materials. It is known that tribochemical reactions without applied voltage form on $\mathrm{SiC}$ surfaces $\mathrm{SiO}_{2}$ layers, which reduce the friction coefficient [5, 11]. The tribo electrochemically formed $\mathrm{SiO}_{2}$ layers in our experiments, however, do not reduce friction and wear. In contrast, the electrochemically enhanced tribooxidation of $\mathrm{SiC}$ leads to higher wear and not to reduced friction. Under cathodic polarization conditions, the $\mathrm{SiC}$ is stable. The current flowing through the surface results in the conversion of the solved in the electrolyte oxygen or the beginning water decomposition. The surface is not altered by the electrochemical reactions. Therefore in this case the change of the electric double layer and as a consequence a change in the apparent viscosity at the electrolyte surface interface are likely to be the most important reason for the observed changes in the tribological behavior. For recharging the double layer, only very low current densities are necessary and the influence of the resistivity of the material must be less pronounced. The $\mathrm{SiC}$ is a semiconductor and the kind of the doping element ( $\mathrm{Al}, \mathrm{B}$, and $\mathrm{N}$ ) and the doping level influence the character and value of the conductivity. At the SiC surface in contact to the electrolyte, the Fermi level shifted and space charge layers are formed. The properties of this layer strongly depends on the carrier concentration and kind in the $\mathrm{SiC}$, i.e., from the local doping of the grains $[63,64]$ and only to a less extend by overall resistance of the materials. These space charge layers influence the formation of the surface potential and double layers and hence the tribological properties. Further detailed investigations of $\mathrm{SiC}$ materials with different well-defined doping levels and conducting character ( $p$-; n-conductor) are necessary to validate this explanation.

In the case of ring-on-ring sliding geometries, the contact area is rather large $\left(552 \mathrm{~mm}^{2}\right)$ and the contact pressure is rather low $(0.2 \mathrm{MPa})$. Under these conditions, the influence of electrochemical potentials is visible when the electric conductivity is sufficiently high. In our investigation the electrical resistance of SSiC-3 was high (7 $\mathrm{k} \Omega$ ), but the diamond-coated surfaces had very good conductivity. As a result, the friction coefficient was varied between 0.025 and 0.06 . On diamond surfaces the formation of solid oxide phases on the surface can be excluded. But it has to be discussed, if only EDL effects are responsible for this change of COF. The electrochemical potentials could also simply reduce the amount or density of dangling bonds in the sliding surfaces that are formed during tribological mechanisms. The passivation of dangling bonds may then reduce adhesion and interaction of surfaces in solid-solid contact events. These tests using ring-on-disk contact geometry show considerable benefits with electrochemical potentials, which may also be obtained in real applications like slide bearings and face seals.

The influence of electrochemical potentials on the COF also strongly depends on the tribological test parameters. At low sliding speeds a higher change of COF was observed. This is an indication for the enhancement of hydrodynamic lubrication, which are assumed to arise due to the formation of an electric double layer (increase of repulsion force, increase of surface near viscosity). 


\section{Conclusions and Outlook}

The friction and wear behavior of different silicon carbide materials in aqueous environment $(1 \mathrm{M} \mathrm{NaCl})$ under electrochemical potentials were investigated. The used materials differ in their corrosion potential and in their corrosion current density due to their unequal material composition. Model friction tests with two different geometries were carried out: pin-on-disk and ring-on-disk. To analyze the influence of electrochemical potentials on friction and wear tests without external potentials (OCP), at cathodic and anodic potentials were conducted. The electrochemical potentials were applied in steps, to analyze the direct influence on the coefficient of friction and reversibility, and constant over the whole testing time. In summary, the most important results of this study were as follows:

- Pin-on-disk tests

* The coefficient of friction can be switched for $\mathrm{SiSiC}$ and $\mathrm{SSiC}-2$ immediately by the application of an electrochemical potential.

* SSiC-1 did not show an instantaneous change of the friction value.

* Friction and wear can be strongly influenced with electrochemical potentials. SSiC-1 shows higher interference with electrochemical potentials as $\mathrm{SiSiC}$, due to different electric conductivities of the materials.

* A correlation of wear volume and electric charge transfer was found. Higher wear is connected to higher electric charge transfer during the test.

- Ring-on-disk tests

* An anodic potential leads to an increase of the coefficient of friction using $\mathrm{SSiC}-3$, whereas at cathodic polarization there is no change in relation without electrochemical potential.

* The coefficient of friction can immediately be changed using Diamond-coated SSiC by $-35 \%$ (cathodic) and $+45 \%$ (anodic).

* At constant electrochemical potentials over a testing time of $60 \mathrm{~h}$ using SSiC-3, there was a strong decrease of the coefficient of friction at cathodic potential.

From these results, we conclude that the main mechanisms are electrostatic repulsion and electro-viscosity. For a more exact validation of this hypothesis, further tests with the ring-on-disk geometry will be conducted using higher pressure, varied ion-concentration and other materials. In addition, from a more application point of view, it would be interesting to make investigations using a two electrode setup.

Acknowledgments The authors gratefully acknowledge the AIF (Arbeitsgemeinschaft industrieller Forschungsvereinigungen, IGFVorhaben 390ZBG019 Tribokorrosion) for funding this project.

\section{Compliance with Ethical Standards}

Conflict of interest On behalf of all authors, the corresponding author states that there is no conflict of interest.

\section{References}

1. Schmalzried R, Schwetz KA (2010) Silicon carbide and boron carbide based hard materials. In: Ceramic science and technology. Wiley, p 131225

2. Divakar R (1994) Ceramics in face seal applications. In: Friction an wear of ceramics. Marcel Dekker, New York, pp 357-383

3. Nau BS (1997) Mechanical seal face materials, proceedings of the Institution of Mechanical Engineers. Part J. J Eng Tribol 211(3):165-183

4. Celis JP, Ponthiaux P, Wenger F (2006) Tribo-corrosion of materials: interplay between chemical, electrochemical, and mechanical reactivity of surfaces. Wear 261(9):939-946

5. Gates RS, Hsu SM (2004) Tribochemistry between water and Si3N4 and SiC: induction time analysis. Tribol Lett 17(3):399-407

6. Saito T, Imada Y, Honda F (1997) An analytical observation of the tribochemical reaction of silicon nitride sliding with low friction in aqueous solutions. Wear 205(12):153-159

7. Jordi L, Iliev C, Fischer TE (2004) Lubrication of silicon nitride and silicon carbide by water: running in wear and operation of sliding bearings. Tribol Lett 17(3):367-376

8. Loeffelbein B, Woydt M, Habig KH (1994) Reibungs- und Verschleiuntersuchungen an Gleitpaarungen aus ingenieurkeramischen Werkstoffen in wSrigen Lsungen. In: Technische Keramische Werkstoffe, J. Kriegesmann, pp. 1-61

9. Presser V, Krummhauer O, Nickel K, Kailer A, Berthold C, Raisch C (2009) Tribological and hydrothermal behaviour of silicon carbide under water lubrication, tribological and hydrothermal behaviour of silicon carbide under water lubrication. Wear 266:771

10. Tomizawa H, Fischer TE (1987) Friction and wear of silicon nitride and silicon carbide in water: hydrodynamic lubrication at low sliding speed obtained by tribochemical wear. ASLE Trans 30(1):41-46

11. Presser V, Nickel K, Krummhauer O, Kailer A (2009) A model for wet silicon carbide tribo-corrosion. Wear 267:168-176

12. Andrews A, Herrmann M, Sephton M, Machio C, Michaelis A (2007) Electrochemical corrosion of solid and liquid phase sintered silicon carbide in acidic and alkaline environments. J Eur Ceram Soc 27(5):2127-2135

13. Sydow U, Schneider M, Herrmann M, Kleebe HJ, Michaelis A (2010) Electrochemical corrosion of silicon carbide ceramics. Mater Corros 61(8):657-664

14. Herrmann M, Sempf K, Schneider M, Sydow U, Kremmer K, Michaelis A (2014) Electrochemical corrosion of silicon carbide ceramics in H2SO4. J Euro Ceram Soc 34(2):229-235

15. Herrmann M, Sempf K, Wendrock H, Schneider M, Kremmer K, Michaelis A (2014) Electrochemical corrosion of silicon carbide ceramics in sodium hydroxide. J Eur Ceram Soc 34:1687-1693 
16. Herrmann M, Sempf K, Kremmer K, Schneider M, Michaelis A (2015) Electrochemical corrosion of silicon-infiltrated silicon carbide ceramics in aqueous solutions. Ceram Int 41(3):4422-4429

17. Sauti G, Can A, McLachlan S, Herrmann M (2007) The AC conductivity of liquid-phase-sintered silicon carbide. J Am Ceram Soc 90:2446-2453

18. Kelsall GH, Zhu Y, Spikes HA (1993) Electrochemical effects on friction between metal oxide surfaces in aqueous solutions. J Chem Soc Faraday Trans 89(2):267-272

19. Ismail M, Harvey T, Wharton J, Wood R, Humphreys A (2009) Surface potential effects on friction and abrasion of sliding contacts lubricated by aqueous solutions. Wear 267(11):19781986

20. Brandon N, Wood R (1993) The influence of interfacial potential on friction and wear in an aqueous drilling mud. Wear 170(1):33-38

21. Su YY, Marek M (1995) Reduction of friction during wire drawing by electrode control. J Mater Eng Perform 4(2):154-160

22. Chang Q, Meng Y, Wen S (2002) Influence of interfacial potential on the tribological behavior of brass/silicon dioxide rubbing couple. Appl Surf Sci 202(1-2):120-125

23. Meng Y, Hu B, Chang Q (2006) Control of local friction of metal/ceramic contacts in aqueous solutions with an electrochemical method. Wear 260(3):305-309

24. Mischler S, Ponthiaux P (2001) A round robin on combined electrochemical and friction tests on alumina/stainless steel contacts in sulphuric acid. Wear 248:211-225

25. Barril S, Mischler S, Landolt D (2001) Triboelectrochemical investigation of the friction and wear behaviour of TiN coatings in a neutral solution. Tribol Int 34(9):599-608

26. Meschke F (2004) Electrically driven cold water corrosion of $\mathrm{SiC}$, in cfi/Ber. DKG 81(8), E19

27. Brandon NP, Bonanos N, Fogarty PO, Mahmood MN, Moore AJ, Wood RJK (1993) Influence of potential on the friction and wear of mild steel in a model aqueous lubricant. J Appl Electrochem 23:456-462. doi:10.1007/BF00707622

28. Kalin M, Novak S, ViPintin J (2006) Surface charge as a new concept for boundary lubrication of ceramics with water. J Phys D 39(15):3138

29. Deryagin B, Smilga V (1994) The effect of the double electric layer on rolling friction (the electrical component of rolling friction). Prog Surf Sci 45:108-118

30. Xu J, Kato K (2000) Formation of tribochemical layer of ceramics sliding in water and its role for low friction. Wear 245(12):61

31. Bai S, Huang P, Meng Y, Wen S (2006) Modeling and analysis of interfacial electro-kinetic effects on thin film lubrication. Tribol Int 39(11):1405-1412

32. Wong P, Huang P, Meng Y (2003) The effect of the electric double layer on a very thin water lubricating film. Tribol Lett 14(3):197-203

33. Zuo Q, Lai T, Huang P (2012) The effect of the electric double layer on very thin thermal elastohydrodynamic lubricating film. Tribol Lett 45(3):455-463

34. Prieve D, Bike S (1987) Electrokinetic repulsion between two charged bonds undergoing sliding motion. Chem Eng Commun 155:149-160

35. Zuo Q, Huang P, Su F (2012) Theory analysis of asymmetrical electric double layer effects on thin film lubrication. Tribol Int 49:67-74

36. Zhang B, Umehara N (1998) Hydrodynamic lubrication theory considering electric double layer for very thin water film lubrication of ceramics. JSME Int J Ser C 41(2):285-290. Anglais

37. Chen M, Kato K, Adachi K (2002) The comparisons of sliding speed and normal load effect on friction coefficients of self-mated Si3N4 and SiC under water lubrication. Tribol Int 35(3):129-135
38. Zhu YY, Kelsall GH, Spikes HA (1994) The influence of electrochemical potentials on the friction and wear of iron and iron oxides in aqueous systems. Tribol Trans 37(4):811-819

39. Li WL, Jin Z (2008) Effects of electrokinetic slip flow on lubrication theory, proceedings of the Institution of Mechanical Engineers. Part J. J Eng Tribol 222(2):109-120

40. Bazant MZ, Kilic MS, Storey BD, Ajdari A (2009) Towards an understanding of induced-charge electrokinetics at large applied voltages in concentrated solutions. Adv Colloid Interface Sci 152(1-2):48-88

41. Kailer A, Amann T, Krummhauer O, Herrmann M, Sydow U, Schneider M (2011) Influence of electric potentials on the tribological behaviour of silicon carbide. Wear 271(910):1922-1927

42. Lu H, Amann T, Kailer A (2012) Electric potentials effects on friction between silicon carbide surfaces in aqueous solutions, in 53. Tribologie-Fachtagung, Goettingen

43. Kailer A, Amann T, Gumbsch P, Krummhauer O (2014) Vorrichtung und Verfahren zum Betrieb eines tribologisch belasteten Bauteils, Nr. 102010009507, Vorrichtung und verfahren zum betrieb eines tribologisch belasteten bauteils, nr. 102010009507

44. Kailer A, Hollstein T, Schwetz K, Nosowicz J (2000) SchSdigungsmechanismen von Siliciumcarbid bei gleitender Beanspruchung in wSssriger Umgebung In: Tribologie-Fachtagung Goettingen, Vortrag Nr. 16

45. Popov VL (2009) Kontaktmechanik und Reibung, Ein Lehr und Anwendungsbuch von der Nanotribologie bis zur numerischen Simulation. In: Kontaktmechanik und Reibung, Ein Lehr und Anwendungsbuch von der Nanotribologie bis zur numerischen Simulation, vol. 1. Springer

46. Spikes H (1997) Mixed lubrication: an overview. Lubr Sci 9:221-253

47. Sempf S, Herrmann M, Sydow U (2012) New ways of revealing the microstructures of $\mathrm{SiC}$ materials. Prakt Metallographie, pp 64-74

48. Conrad T, Arstilla K, Hantschel T, Franquet A, Vanderforst W, Bauer F (2013) Composition quantification of microelectronics multilayer thin films by EDX: toward small scale analysis. Mater Res Soc 16

49. Jones $\mathrm{G}$ (2004) On the tribological behaviour of mechanical seal face materials in dry line contact: Part II. Bulk ceramics, diamond and diamond-like carbon films. Wear 256(34):433-455

50. Schaefer L (2011) Diamantbeschichtete Keramik DiaCer: LeistungsfShiger Werkstoffverbund fnr extreme Anforderungen. Diamond Business, pp 22-26

51. Matthey T, Schruefer A (2011) CVD Diamantinnovation setzt sich durch. Diamond Business, pp 6-9

52. www.eagleburgmann.com

53. Sharma N, Kumar N, Sundaravel B, Panda K, David W, Kamarrudin M, Dash S, Panigrahi B, Tyagi A, Lin IN, Raj B (2011) Effect of $\mathrm{CH} 4 / \mathrm{H} 2$ plasma ratio on ultra-low friction of nano-crystalline diamond coating deposited by MPECVD technique. Tribol Int 44(9):980-986

54. Hinds G (1996) The electrochemistry of corrosion. Corrosion Doctors Publications

55. McCafferty E (2010) Introduction to corrosion science. Springer, p 145

56. Kearns JR (1996) electrochemical noise measurement for corrosion applications. In: Electrochemical noise measurement for corrosion applications. ASTM International, p 111

57. Yamamoto Y, Ura A (1992) Influence of interposed wear particles on the wear and friction of silicon carbide in different dry atmospheres. Wear 154(1):141-150

58. Skopp A, Woydt M (1995) Ceramic and ceramic composite materials with improved friction and wear properties. Tribol Trans 38(2):233-242 
59. Mala GM, Li D, Werner C, Jacobasch HJ, Ning Y (1997) Flow characteristics of water through a microchannel between two parallel plates with electrokinetic effects. Int J Heat Fluid Flow 18(5):489-496

60. Siegelina F, Kleebea HJ, Sigl L (2003) Interface characteristics affecting electrical properties of Y-doped SiC. J Mater Res 18(11):2608-2617

61. Kleebe HJ, Siegelin F (2003) Schottky barrier formation in liquid-phase-sintered silicon carbide. MEKU 94(3):211-217. doi:10.3139/146.030211
62. Schroeder A, Pelster R, Grunow V (1996) Charge transport in silicon carbide: atomic and microscopic effects. J Appl Phys 80:2260-2268

63. Memming R (2001) Semiconductor electrochemistry, 1st edn. Wiley

64. Hamann CH (1998) Elektrochemie, W, 3rd edn. Vielstich, Elektrochemie. Wiley 